\title{
Sucrose and commercially available milk reduced crying in newborns during a blood collection procedure
}

\author{
Blass EM. Milk-induced hypoalgesia in human newborns. Pediatrics 1997 Jun;99:825-9.
}

\section{Objective}

To determine the effectiveness of milk and its components for reducing crying in newborns during and after a blood collection procedure.

\section{Design}

Randomised, double blind, controlled trial.

\section{Setting}

A community hospital in New York, USA.

\section{Patients}

72 vaginally delivered infants ( $42 \%$ boys, $85 \%$ white) with Apgar scores $\geqslant 8$ at 1 minute and $\geqslant 9$ at 5 minutes. $81 \%$ of the infants were breast fed.

\section{Intervention}

Infants were assigned to 1 of 9 treatment groups ( 8 infants per group): sucrose 12\%; Ross Special Formula (a solution approximating human milk containing $7.5 \mathrm{ml}$ protein, $3.24 \mathrm{~g}$ lactose, $1.85 \mathrm{ml}$ fat, and water to make $50 \mathrm{ml}$ ); Similac, a commercially available milk; lactose $7 \%$; fat/lactose (3.5 g lactose, $1.85 \mathrm{ml}$ fat, and water to make $50 \mathrm{ml}$ of solution); fat (1.85 ml of a coconut and soy oil blend and $48.15 \mathrm{ml}$ water); protein $(7.5 \mathrm{ml}$ provimin and $35 \mathrm{ml}$ water); concentrated fat (3.7 $\mathrm{ml}$ fat and $46.3 \mathrm{ml}$ water); or water. 7 minutes before blood collection, the infant's foot was placed in a heated matrix. After 3 minutes, infants drank $2 \mathrm{ml}$ of the designated solution from a syringe for 2 minutes. During the next 2 minutes, the nurse, who was unaware of the treatment condition, prepared for the procedure. For scoring purposes, the procedure began when the nurse squeezed the heel immediately before the heel stick, and ended with the application of a bandage and release of the heel (3-6 minutes). The entire session was videotaped.

\section{Main outcome measures}

Crying (detection of a cry sound) was scored from the videotape by a blinded observer for 2 time periods (during the procedure and during a 3 minute recovery period).

\begin{abstract}
Main results
During the procedure, infants who received sucrose or Similac had reduced crying (cried during $47 \%$ of the procedure, $\mathrm{p}=0.02$; and $73 \%, \mathrm{p}=0.04$, respectively) compared with infants who received water (cried during $92 \%$ of procedure). Lactose, fat, protein, and Ross Special Formula did not reduce crying during the procedure. During the recovery period, infants receiving sucrose, fat (corrected $\mathrm{p}<0.02)$, protein $(\mathrm{p}<0.008)$, or Ross Special Formula $(\mathrm{p}<0.01)$ had reduced crying.
\end{abstract}

\section{Conclusion}

Sucrose and Similac reduced crying among infants during a blood collection procedure, and sucrose, fat concentrations, protein, and Ross Special Formula reduced crying during the 3 minutes after the procedure.

Sources of funding: National Institutes of Mental Health and in part, Ross Products Division of Abbott Laboratories.

For article reprint:Dr E M Blass, Department of Psychology, Tobin Hall, University of Massachusetts, Amherst, MA 01003, USA. Fax +1 6175347297.

\section{Commentary}

Pain management in newborns has been increasingly recognised as an important component of nursing care. This study by Blass evaluates the effectiveness of nonpharmacological nursing interventions in pain relief. The study has several strengths. Data were collected at the same time each day (7-8 am) because endorphin concentrations may vary throughout the day. The nurse who did the heel prick and the person scoring the videotape were unaware of which fluid the infants received. By using one nurse and one video interpreter, interobserver variation was eliminated. A few study limitations should be considered. The primary outcome was crying. While crying is an outcome measure previously studied in response to pain, ${ }^{1}$ the clinical importance of reduced crying is uncertain as it is only one index of the behavioural responses to pain. ${ }^{2}$ Also, the study does not distinguish between procedural pain and hunger cries. While the author states that the infants were "almost always asleep at the time of the experiment", it is uncertain if the state of alertness was uniform across groups. Levels of alertness could alter pain response. ${ }^{3}$ The number of infants in each group was small $(n=8)$; other differences may have reached statistical significance with larger numbers.

Instituting non-pharmacological nursing interventions for pain management is desirable. The study findings indicate that sucrose effectively reduced crying during treatment and recovery which supports previous research. ${ }^{3}$ Similac reduced crying during treatment but not during recovery, and fat solutions, protein, and Ross Special Formula reduced crying during recovery. A large proportion of the infants $(81 \%)$ were breast fed and while the author states that they were "essentially equally distributed among the nine groups", data regarding the precise distribution were not provided. The ethics of offering fully breast fed infants formula or milk components may be controversial. Further trials investigating the effects of milk and its components on biological mechanisms affecting pain response in newborns with larger numbers in each group are warranted.

Shahirose S Premji, RN, MSc(N) Clinical Nurse Specialist/ Neonatal Practitioner Shari Gray, BScPhm Neonatal Pharmacist Bosco Paes, MD Neonatologist Hamilton Health Sciences Corporation Hamilton, Ontario, Canada

1 Johnston CC, Stevens B, Craig KD, et al. Developmental changes in pain expression in premature, full-term, two- and four-monthold infants. Pain 1993;52:201-8.

2 Grunau RV, Johnston CC, Craig KD. Neonatal facial and cry responses to invasive and noninvasive procedures. Pain 1990;42:295-305.

3 Ramenghi LA, Wood CM, Griffith GC, et al. Reduction of pain response in premature infants using intraoral sucrose. Arch Dis Child Fetal Neonatal Ed.1996;74:F126-8. 